REGARDS

SUR L'ECONOMIE ALLEMANDE

BULLETIN ECONOMIQUE DU CRAC

\section{Regards sur l'économie allemande}

Bulletin économique du CIRAC

$80 \mid 2007$

Varia

\title{
Syndicats : une année de choix stratégiques
}

\section{Isabelle Bourgeois}

\section{OpenEdition}

\section{Journals}

Édition électronique

URL : http://journals.openedition.org/rea/710

DOI : $10.4000 /$ rea. 710

ISBN : 978-2-8218-0856-0

ISSN : 1965-0787

Éditeur

CIRAC

Édition imprimée

Date de publication : 1 mars 2007

Pagination : 37-38

ISSN : 1156-8992

Référence électronique

Isabelle Bourgeois, "Syndicats : une année de choix stratégiques », Regards sur l'économie allemande [En ligne], 80 | mars 2007, document 2, mis en ligne le 01 mars 2009, consulté le 15 septembre 2020 URL : http://journals.openedition.org/rea/710

Ce document a été généré automatiquement le 15 septembre 2020

(C) CIRAC 


\title{
Syndicats : une année de choix stratégiques
}

\author{
Isabelle Bourgeois
}

1 Le calendrier 2007 des négociations salariales est chargé, une longue série de conventions tarifaires arrivant à échéance : commerce, assurances, service public, mais aussi contrôleurs aériens, Deutsche Bahn AG ou Deutsche Telekom AG... Comme souvent, c'est la chimie (257 000 salariés concernés) qui ouvre le bal : sa convention a expiré le 31 janvier. La branche et son syndicat IG BCE étant réputés pour conclure des accords habituellement modérés, les négociations en cours préoccupent beaucoup moins l'opinion que la perspective de celles qui s'ouvriront dans la métallurgie (travail des métaux et électrotechnique) après le 31 mars. Il faut dire qu'il s'agit non seulement de la branche la plus importante en effectifs (3,2 millions de salariés), mais aussi de la plus stratégique pour l'économie allemande puisqu'elle rassemble les secteurs-phares les plus exposés à la compétition mondiale et que les salaires qui s'y négocient influent directement sur l'évolution de la conjoncture outre-Rhin tout en servant de référence à la BCE dans ses calculs pour évaluer l'inflation dans la zone euro.

\section{IG Metall : des revendications salariales disproportionnées}

2 Au vu de la forte reprise que connaît l'économie allemande, le syndicat IG Metall a déclaré son intention de redistribuer les fruits de la croissance et prône une très forte hausse des salaires, de l'ordre de $+6,5 \%$. Elle est considérée comme excessive par son partenaire patronal Gesamtmetall, ce qui est normal dans cette phase de début des négociations. Plus important encore, elle est considérée comme démesurée, voire irresponsable par nombre d'observateurs, à commencer par la BCE qui redoute là un risque pour l'inflation. IG Metall, un des acteurs principaux de la longue modération salariale qui avait permis aux entreprises allemandes de renouer avec la compétitivité, et réputé pour son action responsable dans la macro-régulation sociale (voir REA 
72/05) est parfaitement conscient lui aussi de ces risques. Et pourtant, il maintient ses positions.

\section{Une surenchère 'électoraliste'}

3 Plusieurs facteurs l'y incitent. Les caisses de grève d'IG Metall sont bien remplies, ce qui lui permet de mener un conflit musclé et de financer en cas de besoin une grève dure. Plus importante est l'approche de son congrès ordinaire (04/11-11), au cours duquel l'équipe dirigeante doit être renouvelée. Normalement, il est prévu que Jürgen Peters cède son poste à Berthold Huber. Se pose alors la question du choix du nouveau numéro deux. Au moins deux candidats sont en lice : Armin Schild (district tarifaire de Hesse) et Detlef Wetzel (district de Rhénanie du Nord-Westphalie). Alors que, par tradition, l'accord pilote se conclut le plus souvent dans le Bade-Wurtemberg, ils se livrent actuellement à une surenchère pour remporter cet honneur et se profiler meilleur négociateur. Du choix du nouveau directoire dépendra par ailleurs l'équilibre des pouvoirs au sein de la Confédération DGB entre les deux principales formations (sur 8) que sont IG Metall et son homologue des services, Ver.di. Or ce dernier traverse lui aussi une phase difficile : il doit définir les lignes de sa culture lors de son congrès ordinaire (du 29-09 au 06-10).

\section{Chute du nombre d'adhérents aux syndicats du DGB}

4 A ces facteurs somme toute conjoncturels s'en ajoute un autre, de nature structurelle. Les syndicats affrontent un recul du nombre de leurs adhérents qui commence à atteindre aujourd'hui des proportions mettant en danger leur légitimité. De 1990 à 2005, le nombre des salariés affiliés au DGB est tombé de 11,9 millions à 6,8 millions, affirme la confédération syndicale. Le taux d'organisation n'est plus aujourd'hui que de $26 \%$. Si cette chute est due en large partie aux mutations structurelles qui ont modifié, voire brouillé, les périmètres des branches, l'évolution s'est accélérée avec l'unification, nombre d'entreprises décidant de ne pas ou plus s'affilier aux fédérations patronales qui perdent ainsi elles aussi leurs adhérents. Aujourd'hui, IG Metall ne compte plus que 2,33 millions de membres, ver.di, seulement 2,28 millions. Viennent ensuite, loin derrière, IG BCE (729 000), IG Bau (369 000), GEW et Transnet (249000 chacun), NGG (211 000), ainsi que le syndicat de la police (171 000).

\section{Des syndiqués âgés et majoritairement fonctionnaires}

Dans le même temps, la structure des syndiqués s'est modifiée, comme le révèle une étude publiée par l'Institut der Deutschen Wirtschaft (iw-Trends, 4/2006). Si les femmes et salariés à temps partiel ont toujours quelque peu boudé le syndicalisme, ce sont surtout les hommes qui lui tournent désormais le dos, leur taux d'organisation étant tombé de $39 \%$ à $26 \%$ au cours des 25 années écoulées. Seule la cohorte des $40-50$ ans lui reste fidèle $(30 \%)$; les moins de 30 ans n'étant que $15 \%$ à se syndiquer. Si le taux d'organisation des fonctionnaires est de $39 \%$, il chute à $31 \%$ chez les ouvriers et à $15 \%$ seulement chez les employés. C'est parmi les salariés des grandes entreprises que le taux de syndiqués est le plus élevé; dans celles de plus de 2000 salariés, il frise $34 \%$. 
Plus l'entreprise est petite, plus ce taux est faible : il est d'un peu plus de $14 \%$ dans les PME de moins de 50 salariés, de la moitié seulement dans celles comptant moins de 10 salariés. C'est dans cette désaffection progressive et continue que réside le principal défi pour l'avenir du modèle du partenariat social allemand. Dès lors, dans ce contexte national en pleine mutation, les syndicats allemands investissent de plus en plus le champ de la politique européenne et internationale.

INDEX

Mots-clés : IG Metall, négociation, partenaires sociaux, syndicat 